Irish Math. Soc. Bulletin

Number 82, Winter 2018, 4-10

ISSN 0791-5578

\title{
Timothy Gayleard Murphy
}

\author{
RICHARD M. TIMONEY
}

Tim Murphy, as he was known by students and colleagues alike, died on February 15th 2017. He was appointed a lecturer in (pure) Mathematics in Trinity College Dublin on 1st January 1965, and continued to give lectures and supervise projects until the first semester of 2016-17.

Despite his last name, Tim was English and born in London on June 26th, 1933 to scientific parents. His father Alfred was a metallurgist, became a professor in Birmingham and later Principal of Cranfield College in 1955, at a time when the College was seeking to make the transition from an RAF institution to university status. Tim's mother Helen Elaine Blanch Millar was from Jamaica and an organic chemist. Tim was sent to boarding school, Staunton in Somerset, at the early age of six and graduated with a first in Mathematics at St. John's College, Cambridge. He moved to St. Catherine's College for his $\mathrm{PhD}$ under the supervision of the great number theorist Louis Mordell. It is not easy to find out what Mordell was like as a supervisor, but Tim recounted recently to David Malone that his own interest in computing originated from working with Swinnerton-Dyer on code to check out number theoretic conjectures including some that led to the to the famous Birch, Swinnerton-Dyer conjecture. That would have been in the late 1950s or early in the 1960s where the computers would have been very early models. Certainly Cambridge had advantages over other universities in hosting the design and construction of some of the very earliest computers. Wikipedia gives the date 1937 for the start of a general computing service at Cambridge (presumably with human power originally rather than machines), and it was a unit within Mathematics - an arrangement espoused strongly as a philosophy by Tim over many years.

In fact Mordell is said to have formally retired in 1953, but presumably remained more or less active until he died in 1972. Mordell

Received on 19-8-2018; revised 20-11-2018. 
was a professor at Manchester for a long period, moving to Cambridge in 1945. As Tim was born in 1933 his first contact with Mordell must have been around the year of Mordell's retirement. While at Cambridge, Tim got to know Roger Penrose well (they shared rooms) and hatched a plan to write up Penrose's approach to tensor calculus, a plan that never came to fruition despite later efforts to employ MetaFont to typeset the notation. A major influence on Tim was a year (1962-63) he spent in Paris, where he was exposed to many mathematical ideas that seem to have fundamentally affected his interests for the rest of his life. Tim spent the academic year 1970-71 at Essex University.

Tim published very few mathematical papers and one must look elsewhere to understand the depth of the influence he had over his decades at TCD. He was an inspiring lecturer, at least for those who could get used to his style. I mean lecturing style here but it would be remiss of me not to comment on his wardrobe - an Arran sweater he wore in all weathers, decorated with a long red scarf in cold snaps. David Spearman tells me the scarf was one for the Lady Margaret Boat Club, the boat club of St. John's College, Cambridge.

In his lectures, I think he liked to declaim things in a controversial way at times and constructed his lecture courses so as to reflect his own view of the best way to do things, rather than the way that might be used most often by others. I think the course (or module in our modern parlance) that would have seen the largest interaction between Tim and his students would be the 111 Algebra course he gave for many years to first year Mathematics students. It had lecture notes printed on the kind of computer paper we used years ago (used by line printers, with blue horizontal lines and perforated edges where the tractor feed pulled the paper) and spent a huge proportion of its time on multiple choice tests. Tim wrote on the board in the copper-plate script that he also used to fill his spiral notebooks, a very distinctive and clear script. There were one or two lectures each week and then a quiz late on Friday afternoon, a computer graded quiz where the results were fitted to a bell curve. For a beginning abstract algebra course, it dealt with fairly difficult topics such as character tables. 
Over the years, Tim gave quite a variety of modules in algebra and number theory to 3rd and 4th year students. Group representations was a regular one, every other year, and there were also modules shared with Michael Purser on either coding theory or cryptography (in alternate years). Tim's contribution was a somewhat complementary topic, either finite fields to go with coding theory, or information theory for the cryptography. But a really novel thing was a module called Fermat's last theorem delivered in 1993-94. Wiles first announced his proof on Wednesday 23 June 1993, but in fact a proof that was deemed correct had to wait until 1995. Versions of the module that Tim delivered later had less misleading titles.

It would be remiss of me not to mention Math Competitions. Whenever the (Dublin University) Mathematical Society wanted to select a team for an Intervarsity Mathematics competition, or to host one of them, they would rely on Tim to come up with the questions and to grade them. Usually Tim asked for suggestions from colleagues, but for many years he would get little help. In recent years, perhaps this changed and there were attempts to have an extra-curricular class so that students could practice problem solving. While Tim helped, he was no longer the only colleague doing the work.

In a much less mathematical vein, Tim also organised a module on Practical Computing, one lecture a week for a term plus a small group practical on the Unix system of the School of Mathematics. The lectures dealt briefly with many topics in computing - C, Java, web pages, $\mathrm{HT}_{\mathrm{E}} \mathrm{X}$ amongst them, but we turn now to Tim's interests in computing.

While it seems that Tim was always interested in computing, we begin with the UNIX system of the School that started in 1980 with a Digital pdp11/23 computer. Tim persuaded the leaders of the School (Brian Murdoch who was the Professor of Pure Mathematics and David Spearman, the Professor of Applied Mathematics) to use a windfall that came from the Bank of Ireland to buy the pdp. The windfall arose because the Banks were getting adverse publicity for their large profits, and it seems each department in TCD was to get a certain amount of money. Tim was very convinced that a Unix based computer was the way to go (an academic source code license was available from AT\&T if one went through some paperwork). I 
think Digital was the leading manufacturer of mini computers, and the pdp was an affordable option. Besides it was the machine used by Kernighan \& Ritchie to develop the $\mathrm{C}$ programming language, another of Tim's strongly held views being that $\mathrm{C}$ was the language to use (and it is the language for the UNIX operating system). Of course, by todays standards it was incredibly puny, and it absorbed our annual equipment budget to add some RAM (128K extra!) or a math coprocessor.

It was in those days quite a business to boot a pdp without any operating system, even though Tim had a complete system on tape he got from a contact at a UK university. Tim recruited the services of Brendan Lynch, who held a research position in Computer Science. Tim was good at inspiring students and others to put many many hours into the system, and Brendan was in technical charge for some years at the start.

In order for the machine to be usable, we needed a computer room to house terminals (type adm 3a with built in keyboards) and Tim was happy to donate his own office for this purpose. Serial cables were installed by students (and serial wires to staff offices came later). Indeed Tim rarely used whatever office he was assigned and often found a worthy alternative use for it (worthy in his view). In 1980, Tim still had rooms in College and operated between those and more or less public places like the tea room.

Tim believed in allowing students make almost all the day to day decisions about administering the pdp system. Many might regard it as a brave or rash way to do things, but it allowed generations of students to get experience administering a multi-user UNIX system, a deep experience that stood them in great stead for their future careers. They were typically very innovative in their approach as well. That method of running the system persisted until the early 2000s when the paranoia of the powers that be intervened. Amongst the other (non guru) Maths students who did not run the system, there were some who maybe knew enough to be involved in system administration, but many others learned a lot from using the system.

For many years Tim strongly advocated that there be a joint degree in Mathematics \& Computing, one that would be much more theoretical and mathematical than the BA in Computer Science. He often referred to the theories of Dana Scott, for instance. However, Tim never could overcome the opposition of John G. Byrne 
(1933-2016), the Professor of Computer Science. Byrne believed that Pascal was the appropriate language to use for introductory programming, for example, and not C. On Tim's suggestion, we did create and advertise a somewhat virtual 'Computing Option' within the Mathematics programme. It was very popular before the dotcom crash and was reliant on the fact that modules in computing for students of computer engineering (topics such as 68000 assembly language programming, databases, computer graphics) were available to Mathematics students.

A few years post the pdp's arrival, the BBC micro gained in popularity and Tim was attracted to them also, despite the fact that they used BBC basic and that was nothing like UNIX. Later, in 1989, members of staff in TCD collaborated with Apple Computers to run a scheme lending Apple MAC Plus computers to about 100 students. Tim was not formally a part of the project (which was called Project Macintosh (MACintoshes INTO Students $\boldsymbol{H}$ ands) and the principals were Antony Unwin (of Statistics, Project Director), Lorna Harding (Sociology), Seamas O'Buachalla (Teacher Education), Myra O'Regan (Statistics) and James Wickham (Sociology). Their project was to investigate the effect on students of having (or ceasing to have) their own computer. But Tim was well enough known to them that the first year Mathematics students were one of the groups that got loans of the MACs for about 3 separate years.

In 1983 there was an announcement that "the 14th meeting of the European UNIX* Systems User Group will take place at Trinity College in Dublin with Timothy Murphy of the School of Mathematics acting as host and local organiser." It was quite a significant affair and illustrates Tim's international contacts.

An initiative that was greatly appreciated by David Simms (19332018), who ran our departmental research library, was Tim's idea for an online catalogue. It was initially software written by Tim based on a UNIX program called refer, but it was refined considerably by a student Simon Brown (whose father was in fact the TCD librarian at the time). Over time more has been done to it including a web interface by Sharon Murphy (no relation), but we are still using essentially the same system.

Tim was also very interested in Donald Knuth's $\mathrm{T}_{\mathrm{E}} \mathrm{X}$ system, though he was also an early advocate of $\mathrm{HT}_{\mathrm{E}} \mathrm{X}$ (designed by Leslie 
Lamport). It seems $\mathrm{T}_{\mathrm{EX}}$ was initially developed on a pdp-10 in 1978, but a rewrite $\mathrm{T}_{\mathrm{E} X 82}$ was associated with the Pascal language and required a 32 bit computer (while out pdp11/23 and subsequent replacement pdp11/73 were 16 bit machines). Eventually we got an IBM $386 \mathrm{PC}$ clone in the office and an attached Apple Laser printer to cater for $\mathrm{AT}_{\mathrm{E}} \mathrm{X}$ (and $\mathrm{T}_{\mathrm{E}} \mathrm{X}$ ). Prior to that we had a Diablo printer, a fancy daisy wheel printer in its day, and [4] is early evidence of Tim writing a device driver for it. As with the BBC micros and MACs, we relied on serial lines and a programme called kermit to transfer $\mathrm{AT}_{\mathrm{E} X} \mathrm{X}$ source files from the pdp (where we usually used a line editor called em, a vast improvement on ed, to create the files). In those days, running a modestly long document through $\mathrm{HT}_{\mathrm{E}} \mathrm{X}$ would take several minutes, and of course we would need to repeat the compilation to sort out compile time errors. Earlier $\mathrm{AT}_{\mathrm{E} X} \mathrm{X}$ was available on a computer Lab VAX, even harder to interact with.

Tim, an unlikely entrepreneur given his lifelong left-wing views and his membership of the Labour party in Dun Laoghaire, set up a campus company to typeset stuff using $\mathrm{AT}_{\mathrm{E}} \mathrm{X}$ and I guess he diversified into being a distributor for AT\&T Unix for IBM PCs. He was an early advocate for Linux and (in the latter 1990s) used to bulk buy Red Hat installation CDs, which he then offered to students for a nominal fee.

Another capitalist venture (I am not quite sure where the proceeds ended up) was a summer school for young students (called Summer School for Schools) that ran successfully for quite a few years on our system. It was an introduction to UNIX and $\mathrm{C}$ programming and largely run by students (on our terminals). Some of the participants were very young and perhaps there was a worry that some were too young, but it was a successful venture in the days before we ever thought of Garda vetting or the like. Another venture was a 'Student Summer Jobs Scheme' where Tim found interesting projects for students to work on

In fact as many papers [4, 5, 7, 6] about $\mathrm{T}_{\mathrm{E} X}$ survive as formal mathematical publications Tim wrote. I guess he was a regular at the annual meetings of TUG, the $\mathrm{TEX}_{\mathrm{X}}$ User Group. He was very proud that he managed to have Donald Knuth invited as Donegall Lecturer in TCD in 1982. The Donegall lectureship is old (1668), funded by a benefaction to TCD, but unfortunately the benefaction produced income that declined in real terms over the centuries. It 
became a way to top up the salary of a professor of Mathematics, but even that stopped. Tim's colleague Trevor West managed to have the fund resurrected and re-purposed as a distinguished visiting lectureship. For some years there was a stellar line up of lecturers but that has also stopped again in this century.

For many years, Tim produced ATEX notes on his advanced lecture courses and these show a remarkable appreciation of current mathematical trends, as I mentioned above. These notes are available on the web, though definitely not presented in a slick way.

Tim was a regular at the Colloquium until quite recently and would always have insightful questions for the speaker. He was also an incessant contributor to newsgroups including sci.math and sci.math.research, but I think there is no way to retrieve those contributions now.

Tim looked slimmer and trimmer than ever near the end of his life, but he was grief stricken by the passing of his daughter in autumn 2016 and soon afterwards he was diagnosed with cancer. He is survived by his wife Anne, brother Paul (who led the particle Physics group at Manchester from 1965 to 1991 and was awarded the Rutherford medal jointly with J. Thresher in 1980), two sons by a former marriage and 3 grandchildren.

\section{REFERENCES}

[1] Timothy Murphy, Corrections: "The dissection of a circle by chords" (Math. Gaz. 56 (1972), no. 396, 113-115), Math. Gaz. 56 (1972), no. 397, 235-236. MR 0500446

[2] _ The dissection of a circle by chords, Math. Gaz. 56 (1972), no. 396, 113-115. MR 0500445

[3] - On the tensor system of a semisimple Lie algebra, Proc. Cambridge Philos. Soc. 71 (1972), 211-226. MR 0299647

[4] _ Diabolic TEX, TUGboat 2 (1981), no. 3, 15-21.

[5] _ PostScript, QuickDraw, TEX, TUGboat 12 (1991), no. 1, 64-65.

[6] _ JAVA and $T_{E} X$, TUGboat 20 (1999), no. 3, 307-312.

[7] - Abstract: The Penrose notation: a ETEX challenge, TUGboat 21 (2000), no. 3, 291.

[8] Timothy Murphy and T. T. West, Inner products in Banach spaces and supports of Radon measures, Proc. Roy. Irish Acad. Sect. A 69 (1970), 55-61 (1970). MR 0259575

Richard Timoney was a colleague of Tim Murphy's from January 1980.

School of Mathematics, Trinity College Dublin

E-mail address: richardt@maths.tcd.ie 